\title{
Wondering for the future of biotech
}

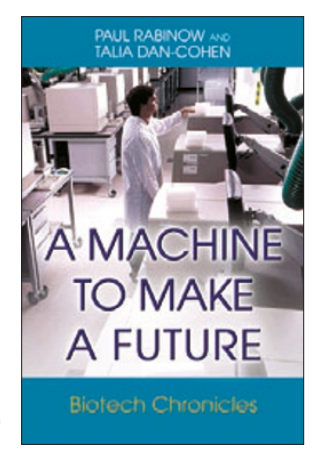

Through a series of interviews with participants and stakeholders, $A$ Machine to Make A Future 'chronicles' the life of Celera Diagnostics, extended kin to Celera Genomics, the company whose speed and ambition did so much to accelerate the sequencing of the human genome. But authors Paul Rabinow and Talia Dan-Cohen focus as much on kairos (timing) as chronos (sequential time), and the result reads like an epic in progress, full of sudden and emotional twists, and no promise of resolution. This is highbrow reality TV for biotech geeks: Cut to a close up on Victor Lee, attorney for Celera Diagnostics. RABINOW, off camera: "So you're not emotionally damaged when the mail comes in?" LEE: "Patent attorneys take rejection very well."

This emphasis on the affective life of the company will likely resonate with anybody who has tried to tinker together novel configurations of technology and people: "I just wanted to pick up something and throw it at the machine." And the difficulties of scaling up even an "information" technology like biotech become apparent as the concepts shift from the confident and deliberate practices of "decoding" the genome and become more fluid and turbulent: "We conceptualized how we were going to do it, in terms of moving liquid around in tubes and plates and... quickly came to the conclusion that we were going to do this at a level that no one has attempted to do before in this particular format."

Because the interviews owe so much to their context, the format is both a strength and a weakness of the book. Much of the account depends upon an understanding of the tacit knowledges and in situ feelings of the participants, and so the reader inevitably wonders after the principles of selection the authors have used with the interview material. Such wonder at an imagined cutting room floor is part of what makes this book so engaging, but it would be worth releasing as much of the archives as possible. Some conversations refer to events to which readers are not privy, and this of course only stokes the reader's curiosity, like missing evidence in a detective story.

Richard Doyle is in the Science, Medicine, Technology \& Cultures Program in the Department of English at The Pennsylvania State University.

e-mail:mobius@psu.edu
And some of the book's treatment of the history of genomics has its own missing evidence: Rabinow, for example, frequently characterizes 'academic critics' of genomics as do-gooders allergic to corporate imperatives, but fails to mention the consistent and coherent critiques of molecular reductionism from both within and without the sciences that accompanied genomics from the beginning. These critiques (for example, those of Evelyn Fox Keller and Richard Lewontin) questioned the very paradigm that was pushing early genomics, and argued that monocausal genetic accounts of disease were insufficient to the multivariable domains of health. The book indeed chronicles a paradigm shift from monogenic to polygenic accounts of disease, and Celera's search for "constellations" of genes that would correlate with illness implicitly recognizes the value of those critiques.

Readers and participants alike would likely also welcome a glance at open-source alternatives to patent-based intellectual property paradigms, as within this epic tale star-crossed biotech seems to block its own progress with a constellation - not of genes, but of patents. Given the focus on the corporate context of biotech, readers will also wonder about the role of only minimally transparent capital markets in shaping this particular future. But such wonder is healthy, and the book encourages such wondering with its careful presentation of the messy, real-life contexts in which the health futures of a planet fluctuate and finally cohere into the present.

The book argues both explicitly and implicitly that a future is anything but determined by the present, and after the ambition and speed of 1990 s genomics, it is worth pausing to wonder. Close on Kathy Ordonez, president of Celera Genomics, on the completion of the sequencing of the human genome. ORDONEZ: "We suddenly just had time to think!" In this context, A Machine for Making a Future lives up to, is, its title.

\section{New books of interest}

\section{Glowing Genes: A Revolution in Biotechnology \\ by Marc Zimmer}

Prometheus Books, 2005, 221 pp. hardcover, \$28

ISBN 1-59102-253-3

Is Human Nature Obsolete? Genetics, Bioengineering, and the Future of the Human Condition

edited by Harold W. Baillie and Timothy K. Casey

The MIT Press, 2005, 440 pp. paperback, \$27

ISBN 0-262-52428-7

Blood Lines: An Introduction to Characterizing Blood Diseases of the Post-Genomic Mouse

by Donald Metcalf

AlphaMed Press, 2005, 251 pp. hardcover

ISBN 1-880854-29-5 